\title{
Research on the Performance Evaluation of Public Investment in Rural Areas Based on DEA Network Model
}

\author{
Zhangxuan Lan* \\ Quzhou University, Quzhou 324000, Zhejiang, China \\ *lanzx2012@163.com
}

\begin{abstract}
With the accelerated process of industrialization and urbanization, traditional agriculture begins to transform to modern agricultural mode. In order to develop modern agriculture, it is not only to reform the existing economic system, but also to increase public investment in rural areas, to create a good economic environment for agricultural development. In this paper, the author analyzes the performance of public investment in rural areas by using DEA network model, the data was selected from 25 provinces. Based on the empirical analysis, the result shows that the efficiency of rural public investment is low, and the difference between regions is obvious. By constructing the SFA model, we find that the technical efficiency and scale efficiency has been significantly improved after adjust initial input amount. Therefore, the government should increase the rural public investment, and pay attention to the efficiency of the funds use.
\end{abstract}

Keywords: DEA network, rural public investment, rural economy, performance evaluation, modern agriculture

\section{Introduction}

With the rapid development of industrialization and urbanization, agriculture will be transformed from the traditional agricultural high input and low output mode to the modern agricultural development mode. The Chinese government put the development of modern agriculture, building a new socialist countryside, as a contemporary historical mission to complete, at all levels of the government promulgated and strengthen a series on modern agricultural development policies and measures, provides the powerful safeguard for the development of China's modern agriculture. Public investment in rural areas as the provider of public goods in rural areas is the main source of funding, to solidify the foundation of agriculture, promote economic and social development in rural areas and farmers continued to increase, narrowing between urban and rural areas people's living standards and public service gap played an important role[1]. In the past decades, the government has tilted the city and industry in public investment policy, and the result is that the income gap between urban and rural areas has increased continuously. The development of modern agriculture and the prosperity of the rural economy, not only to reform the existing economic system, but also to increase public investment in rural areas, to create a good economic environment for agricultural development. Study on the performance evaluation of public investment in rural areas can promote the optimal allocation of public resources [2-3]. The scarcity of resources requires us to use resources effectively. The classical economic school thinks that the "invisible hand" of the market economy can promote the efficient allocation of resources and improve the efficiency of resource utilization. However, due to the existence of market failure, the market economy system in the field of public goods is not able to automatically optimize the allocation of resources; the same is true of rural public investment. Some social essential public goods,

Zhangxuan Lan is the corresponding author. 
such as roads, bridges, public health, environmental protection and so on, private investment is not effective, the government will act as the role of public investors. As an important part of public resources belong to economic resources, public resources performance will also pursue the maximization of social utility. And the private sector, public resources performance evaluation is not directly based on the input output form of currency measure, which is decided by the social welfare of public resources, some in the improvement of the level of social welfare cannot by monetary indicators effective measurement. So, it is very important to measure the efficiency of public investment from the perspective of social welfare.

Study on the performance evaluation of rural public investment can promote the effective provision of public goods in rural areas. In recent years, the state finance has continuously increased the intensity of rural public investment, but for the vast rural areas, the supply of public goods is still far from meeting the needs of the people. Limited to the state finance for the rural public investment resources are limited, the research on performance evaluation of public investment in rural areas is to solve the problem of limited resources make full use, the maximum improve the rural public infrastructure construction, the maximum of providing farmers with the most urgent need of public goods will have an important role. Study on the performance evaluation of public investment in rural areas can promote the improvement of the efficiency of government work. Improve the efficiency of government work is to achieve a smooth transformation of government functions, improve the ability of the party and the government to build the people's satisfaction with the service of the government's important guarantee. Public investment in rural areas is the party and government to build an important part of a harmonious socialist society, rural public investment performance of a useful find out problems existing in the process of investment in government, and construct effective resource allocation system and incentive and restraint mechanism in the process of public investment, reduce the rent-seeking behavior in the government public sector, improve the work efficiency of the government.

\section{Literature Review}

\subsection{Rural Public Investment}

The definition of the concept of public investment, first of all, the understanding of the formation of capital is a must. The understanding of capital formation in economic circles is also a gradual process. Modern economists Keynes put more attention to the formation of physical capital, which the net increase in the amount of material capital investment. The beginning of the sixties of the 19th century, economists began to emphasize labor create income ability is the capital, the improvement of the quality of the labor force and application of advanced knowledge of science and technology, expected to increase future output, human capital of the net increase is considered to be a part of the investment, accordingly, people began to investment and future earnings associated. With the concept of material capital being replaced by the concept of generalized capital, the concept of material capital investment has been replaced by the concept of generalized capital investment [4]. Public investment is generally defined on the grounds of the central and local governments will invest in the form of fixed capital, because the government is not in the micro level directly involved in business activities in the field of special, the government investment is often limited in the specific field of public service, so the capital called public investment, also known as the government investment. Public investment is one of the main tools for the government to regulate the economy.

Public investment in rural areas has the general attributes of public investment; as the government to adjust the economy the main tool, the public investment in rural areas is government in micro level intervention an important means of agricultural economic 
activities, promote the government macroeconomic policies are effectively implemented. On the other hand, the public investment in rural areas of rural public products in the field of social economy in rural areas is an essential, to increase farmers' income, improving people's livelihood, narrowing the gap between the rich and the poor and plays a fundamental role. Generally speaking, public investment is the investment of public goods, which is an important tool for the government to make up the market failure and control the macro economy[5]. The purpose of public investment is to provide public goods, create a good market environment, reduce the cost of social production, and promote the maximization of social welfare. The study of public investment is from the discussion of public issues. In public investment and economic growth, classical economic school representative Ricardo believes that investment in public works while in the field of public works construction to increase employment, however, investment in public works construction from reduction in other sectors to invest, thus increasing the public engineering investment cannot fundamentally solve the problem of employment. Economists Wagner put forward the increasing financial expenditure rule; he believes that industrialization of a country economic development and national finance expenditure pure in one kind of functional relation, with the function of the country's expansion and economic development, to ensure the exercise of the functions of the state financial expenditure will continue to increase[6]. He took the lead to government spending growth is divided into political and economic factors, the so-called economic factors refers to industrial development to promote the process of urbanization, population will be intensive, which will generate congestion externality, it also needs the government management and regulation work. In the early twentieth Century, economists began to reevaluate the role of public investment in economic growth. American economist Rostow pointed out economic development stage theory on public investment spending, public spending in the early stages of economic development for major, growing faster than, because the large number of investment in infrastructure and some capital goods, long period, income is relatively small, private capital accumulation is limited, the private sector is not willing to, also does not have the ability to participate. Therefore, it is necessary to provide by the government. Public investment spending in the middle stage of economic development, the government should continue to invest in public investment, but at this time the government investment is only a supplement to private investment. In this period the characteristics of public investment is on private consumption goods countervailing public investment.

\subsection{Performance Evaluation}

Performance is the result of various actions taken by an organization or an individual in order to achieve a certain objective, namely, the results and effects of the action. Performance evaluation is refers to the use of certain evaluation method, quantitative index and evaluation standard, of departments or organizations to achieve the degree of realization of its functions as determined by performance objectives, and to achieve this goal the arrangements of the budget execution results of comprehensive evaluation. Performance evaluation of the concept source in science and modern enterprise management concept, its purpose is mainly used to organize the staff performance appraisal, on employee compensation decisions, and provide basis of work plan and budget assessment and human resource planning provides information[7]. About 1980s performance evaluation concepts are gradually introduced into the government's public management. Its main purpose is to evaluate the investment efficiency of government departments, to tap the internal potential and improve the output. As a new mode of government management and evaluation of government performance management tools in practice to improve through the performance evaluation system of government strategy, including the strategic objectives of the government's determination, the system design of performance goals, performance information collection, performance evaluation, 
performance feedback and performance evaluation results of the application, government functions and strategy and performance management is connected, in order to promote the continuous improvement and enhance the performance of the government departments.

Performance evaluation of public investment is an important part of government performance evaluation, so performance evaluation for the public sector than the private sector that benefits, costs and expenses are very clear; private sector performance evaluation is simple and clear. First, the benefits of a public project are not effectively measured, and the private sector is able to calculate the output, and the cost of investment, in a very good way. The measurement of public sector revenue is much more complex. Some benefits cannot be based on the effective measurement of money, according to a number of economic indicators to determine the quality of the performance of public projects[8-9]. On the other hand, we cannot determine how much public resources, too much public resources will result in waste of resources, the shortage of resources will lead to unable to meet the public demand, cannot produce the desired economic results. This is also more concerned about the issue of economics. In theory, it is generally assumed that the optimal supply of public goods satisfies the Samuelson condition, that is, the utility of the public goods to all the beneficiaries and the marginal cost. But individuals generally do not want to disclose their true preferences for public goods, the marginal revenue of public goods on their own. Therefore, the supply of public goods is not too much is insufficient. The discussion on the preference of public goods and the optimal supply of public goods has not yet come to an effective solution. Public investment in rural areas as an important part of the national fiscal expenditure, with the continuous increase of the funds of the Chinese government to solve the "three rural issues", it is necessary to gradually strengthen rural public investment funds performance evaluation, give full play to the functions of government public service, prior, during and after the whole process supervision of rural public investment in the use of funds, reduce the rent-seeking behavior of the government and relevant departments in charge of, urge the government and relevant departments in charge of effectively manage and use the public of public financial resources, improve the use efficiency of the rural public investment funds.

\section{The Research Object and Methods}

\subsection{The Object of Study}

The understanding of public expenditure in western countries is the logic starting point of "market failure", to confirm the rationality and necessity of the existence of public expenditure, and to define the scope of public expenditure. Market failure is the basis of the existence of public expenditure, the market cannot solve the problem, it should be borne by the government expenditure responsibility. The object of the performance evaluation of public investment in rural areas of China mainly refers to the object of the rural public investment, that is, the rural public funds flow to the various fields of rural areas[10]. According to the relevant characteristics of public goods and the relevant theoretical basis, this paper defines the following areas as the object of public investment in rural areas:

1) Rural social security: social security system is a prerequisite to promote social fairness, maintain social reproduction and the normal operation of the economy, the government is the responsibility of promoting social security. China's social security system includes social insurance, social relief, social welfare and social care of four parts. Among social assistance belongs to the lowest levels of social security measures, social insurance is the basic level, the social security act, the social welfare column to the highest level and social special care and placement is special level of support activities. 
2) Rural infrastructure: infrastructure including social science education, laws and regulations, and medical and health facilities and infrastructure has the characteristics of public goods, economic theory and social practice has proved that, the low efficiency of the private supply of public goods, prompting the government to serve as the role of the supply of public goods. Although in recent years, remarkable achievements in agriculture and rural infrastructure construction in our country, rural production and living conditions improved significantly, but generally speaking, rural infrastructure is still lagging behind. Agriculture is still a weak link in the national economy and social development.

3) Rural public health: public health is financed by the government or the public sector to a community, regional and national residents to provide free or low-cost health services, to protect the people's health. Under the condition of market economy, "the health service to public health" divided into the government and the public sector to provide social public goods "'". Specifically, rural public health should include rural basic medical care, immunization, maternal and child health, rural drinking water safety in rural areas as well as the food sanitation field.

4) Rural basic education: including ordinary elementary education, junior secondary education and senior secondary education in basic education. At the present stage of China's ordinary primary education and junior secondary education is compulsory education requirements, achieved popularity nationwide. Basic education is a public service, and the government is the agency executive management of public affairs on behalf of the citizens, the Chinese government core position in the basic education and the leading role.

\subsection{DEA Model}

BCC model in variable scale return (VRS) to measure the production efficiency, to the decision making unit (DMU) technology is invalid decomposition of pure technology is invalid and the scale is invalid. Assuming that there is DMUs $\mathrm{N}$, each DMU in the $\mathrm{m}$ inputs to produce $\mathrm{s}$ kinds of output, the classic BCC model input oriented formula for the next:

$$
\begin{gathered}
\min \quad \theta_{b}-e\left(S_{j}^{-}+S_{j}^{+}\right) \\
\text {Subject to } \quad \theta_{b} x_{o}-X \lambda-S_{j}^{-}=0 \\
Y \lambda-S_{j}^{+}=y_{0} \\
e \lambda=1
\end{gathered}
$$

Where $X=\left(x_{j}\right) \subset R^{m \times n}, Y=\left(y_{j}\right) \subset R^{s \times n}, \lambda \subset R^{n}$,

In this formula, e as a unit column vector, $S_{j}^{-}$and $S_{j}^{+}$are slack variables, assuming the above linear programming to optimal parameters for, $\theta$ is the value of the technical efficiency, BBC valid definition of linear programming solution satisfies $\theta^{*}=1$, and slack variable as 0 . The decision unit effective production frontier, by above knowable, and any effective production frontier deviation will lead to the technical inefficiency, deviation degree is higher, the lower the efficiency of technology. The three stages DEA model pioneered by Fried (2002) development. For the evaluation of the effectiveness of the decision making unit is mainly based on the following three stages. The first stage is initial DEA performance evaluation, the initial performance evaluation using the original DEA input and output data to calculate DNUs efficiency. In the second stage, the SFA model is constructed by constructing the SFA model, which is not effective, the environmental factors and the effect of random error on the efficiency. The third stage, according to the 
adjusted input and output variables, repeat the first phase of the process, get the results after excluding the environmental factors and random error factors.

\subsection{Variable Selection}

Choosing the right decision unit and the representative input and output variables have a key effect on the correct use of the three stage DEA model to evaluate the efficiency of the decision making unit. According to the conditions of decision making unit DEA model choosing and decision making units must be as a production unit of the same nature, the homogeneity of the decision making unit mainly includes two aspects, individual decision making units with similar goals and perform similar work; all the DMUs are in the same environment. Previous studies on public investment in rural areas for the input of the majority of scholars concentrated in the national finance to the agricultural production expenditure, including support rural production expenditure and agriculture, forestry, meteorology and other departments of the business cost, agricultural capital construction expenditure, cost of agricultural science and technology. In this paper, we choose takes the following five indicators as the input of rural public investment: investment in agriculture, forestry and water affairs total investment, rural education, rural health and social security and social welfare investment, investment of water conservancy, environment and public utilities management, rural public management and social organization input. Selected three representative output indicators to measure the level of rural public investment performance from the angle of economic benefits and social benefits, respectively, for agriculture, forestry, animal husbandry and fishery increase value, per capita net income of farmers increased value and added value of per capita consumption expenditure of farmers.

Congenital conditions as agricultural production and natural environment, is one of the main factors affecting the efficiency of public investment in rural areas, compared to the natural environment, economic conditions are factors including more human activities, because of historical factors, cultural and national policy guidance, economic level of each area of our country also vary widely,. In comparison, the more developed eastern coastal area economy, economic development in the central and western regions is relatively backward, better economy, the degree of marketization development better, improve infrastructure, education, medical and other livelihood security system construction is relatively perfect, the external effects of economic development will benefit all sectors of society. This article selects the rural labor force quantity, may use the land area and so on as the exogenous variable, the variable situation as shown in Table 1.

Table 1. Variable Description

\begin{tabular}{|c|c|c|}
\hline Variable type & Variable & code \\
\hline \multirow{4}{*}{ Input variables } & Agriculture Forestry and water affairs & nlm \\
\cline { 2 - 3 } & Rural Education & edu \\
\cline { 2 - 3 } & Rural health, social security & wsf \\
\cline { 2 - 3 } & Water environment and management of public utilities & shg \\
\cline { 2 - 3 } Output variable & $\begin{array}{c}\text { Rural public management and social organization } \\
\text { investment }\end{array}$ & pub \\
\cline { 2 - 3 } & $\begin{array}{c}\text { added value of agriculture, forestry, animal husbandry and } \\
\text { fishery }\end{array}$ & $\mathrm{pv}$ \\
\cline { 2 - 3 } & Increase in per capita consumption expenditure & ai \\
\cline { 2 - 3 } & price index & pr \\
\hline environment & Rural labor force \\
\hline
\end{tabular}




\begin{tabular}{|c|c|c|}
\hline \multirow{2}{*}{ variable } & Available land area & tg \\
\cline { 2 - 3 } & Rural residents own productive assets & ngc \\
\cline { 2 - 3 } & Environmental condition index & inv \\
\cline { 2 - 3 } & Economic development index & eco \\
\hline
\end{tabular}

\section{The Empirical Analysis}

\subsection{The Initial Stage of DEA}

On the processing of output indicators, this article eliminates the impact of the price level differences between the various provinces. Scholars also pointed out that because of China's large land area, natural conditions; income level gap between large, non-tradable goods and services in the region, the price difference between domestic regions will be more significant. The corresponding price level is higher in the region with higher nominal income level, and the gap between the actual income levels of the residents in the region is smaller than that of the nominal income. Therefore, the adjusted data of the price index can reflect the actual difference between the income and consumption level. This paper selects rural public investment related input output data from 25 provinces as a sample, year from 2014-2015, using traditional DEA-bcc model on rural public investment efficiency analysis and initial efficiency scores of 2014 as Table 2 shows. Among them, Te means technical efficiency, Pte means the pure technical efficiency, SE menas the scale efficiency, Te= Pte* Se; IRS means the scale of returns, DRS means the scale of diminishing returns, - means the scale of return on the same scale.

Table 2. The Initial Efficiency Score in 2014

\begin{tabular}{|c|c|c|c|c|c|c|c|c|c|}
\hline province & Te & Pte & Se & & province & Te & Pte & Se & \\
\hline Hebei & 0.558 & 0.561 & 0.994 & drs & Hunan & 1.000 & 1.000 & 1.000 & - \\
\hline Shanxi & 0.573 & 0.589 & 0.973 & drs & Guangdong & 0.783 & 1.000 & 0.783 & drs \\
\hline Neimenggu & 1.000 & 1.000 & 1.000 & - & Guangxi & 1.000 & 1.000 & 1.000 & - \\
\hline Liaoning & 0.406 & 0.529 & 0.767 & $\mathrm{drs}$ & Hainan & 1.000 & 1.000 & 1.000 & - \\
\hline Jilin & 0.826 & 1.000 & 0.826 & $\mathrm{drs}$ & Sichuan & 0.856 & 0.87 & 0.984 & $\mathrm{drs}$ \\
\hline Heilongjiang & 1.000 & 1.000 & 1.000 & - & Guizhou & 1.000 & 1.000 & 1.000 & - \\
\hline Jiangsu & 0.801 & 1.000 & 0.801 & $\mathrm{drs}$ & Yunnan & 0.660 & 0.661 & 0.999 & irs \\
\hline Zhejiang & 0.586 & 1.000 & 0.586 & $\mathrm{drs}$ & Shaanxi & 0.949 & 1.000 & 0.949 & $\mathrm{drs}$ \\
\hline Anhui & 0.515 & 0.686 & 0.751 & $\mathrm{drs}$ & Henan & 0.567 & 1.000 & 0.567 & $\mathrm{drs}$ \\
\hline Fujian & 0.469 & 1.000 & 0.469 & & Ningxia & 1.000 & 1.000 & 1.000 & - \\
\hline Jiangxi & 0.764 & 0.838 & 0.912 & $\mathrm{drs}$ & Qinghai & 0.949 & 1.000 & 0.949 & $\mathrm{drs}$ \\
\hline Shandong & 0.318 & 1.000 & 0.318 & $\mathrm{drs}$ & Gansu & 1.000 & 1.000 & 1.000 & - \\
\hline Hubei & 1.000 & 1.000 & 1.000 & - & mean & 0.787 & 0.909 & 0.867 & \\
\hline
\end{tabular}

From the Table 2, we can get that 2014 China's initial public investment in rural areas of the technical efficiency is 0.787 , the average technical efficiency as 0.909 , the average scale efficiency as 0.867 . Under the conditions of current production levels unchanged, reducing the investment $21.3 \%$ can achieve efficient production frontier, technical efficiency decomposition must reduce $9.1 \%$ of the input to the pure technical efficiency, adjustment factor input structure, reduce $13.3 \%$ of the investment reaches the effective size. Specifically, there are 19 provinces in the efficient production frontier, the pure technical efficiency of the provinces have 19, the effective size there are 11 provinces, the remaining provinces is in pure technical efficiency and scale efficiency exist different degree improvement space. 2015 initial efficiency score as shown in Table 3.

Without considering the external environment variables and random factors, various provinces of China rural public investment efficiency value was 0.708 in 2015, the 
average pure technical efficiency scale efficiency was 0.786 , average is 0.895 . Under the conditions of current production levels unchanged, reducing the investment of $29.2 \%$ can achieve efficient production frontier, technical efficiency decomposition must reduce $21.4 \%$ of the input to the pure technical efficiency, adjustment factor input structure, reduce $10.5 \%$ investment reaches the effective size. The specific point of view, only one third of the provinces in the efficient production frontier, respectively, Shanxi, Liaoning, Heilongjiang, Hainan, Qinghai, Ningxia, pure technical efficiency provinces 13, the effective size of provinces have eight. The remaining provinces are in the pure technology efficiency and scale efficiency exist different degree improvement space. The technical efficiency of each area varied greatly. The technical efficiency scores of 8 provinces is lower than 0.5, the lowest efficiency score was 0.351, 0.305 in Hubei, Hunan, and more than $60 \%$ of the investment is invalid input.

Table 3. The Initial Efficiency Score in 2015

\begin{tabular}{|c|c|c|c|c|c|c|c|c|c|}
\hline province & Te & Pte & Se & & province & Te & Pte & Se & \\
\hline Hebei & 0.518 & 0.559 & 0.927 & drs & Hunan & 0.305 & 0.429 & 0.711 & drs \\
\hline Shanxi & 1.000 & 1.000 & 1.000 & - & Guangdong & 0.41 & 0.572 & 0.717 & drs \\
\hline Neimenggu & 1.000 & 1.000 & 1.000 & - & Guangxi & 0.408 & 0.439 & 0.93 & irs \\
\hline Liaoning & 1.000 & 1.000 & 1.000 & - & Hainan & 1.000 & 1.000 & 1.000 & - \\
\hline Jilin & 0.979 & 1.000 & 0.979 & drs & Sichuan & 0.634 & 1 & 0.634 & drs \\
\hline Heilongjiang & 1.000 & 1.000 & 1.000 & - & Guizhou & 0.409 & 0.508 & 0.805 & irs \\
\hline Jiangsu & 0.584 & 1.000 & 0.584 & drs & Yunnan & 0.424 & 0.437 & 0.969 & irs \\
\hline Zhejiang & 0.816 & 1.000 & 0.816 & drs & Shaanxi & 0.552 & 0.693 & 0.796 & drs \\
\hline Anhui & 0.542 & 0.63 & 0.86 & drs & Henan & 0.567 & 1.000 & 0.567 & drs \\
\hline Fujian & 0.91 & 1.000 & 0.91 & drs & Ningxia & 1.000 & 1.000 & 1.000 & - \\
\hline Jiangxi & 0.472 & 0.498 & 0.947 & drs & Qinghai & 1.000 & 1.000 & 1.000 & - \\
\hline Shandong & 0.84 & 1.000 & 0.84 & drs & Gansu & 0.745 & 0.796 & 0.937 & drs \\
\hline Hubei & 0.351 & 0.361 & 0.974 & drs & mean & 0.708 & 0.786 & 0.895 & \\
\hline
\end{tabular}

\subsection{SFA Stage}

In order to accurately reflect the efficiency of public investment in rural areas of China, we will use the stochastic frontier analysis method (SFA) to separate the effects of environmental variables and random factors. Will first stage DMU of each input variable relaxation (radial amount of slack and non-radial amount of slack) as explanatory variables and explanatory variables were selected for the above environmental variables, SFA regression analysis by using Stata 12.0, Slacks1 means behalf of agriculture, forestry and water affairs relaxation; slacks 2 represents the church education amount of slack; relaxation quantity on behalf of the slacks3 rural health, social security and social welfare; slacks4 representative of water conservancy, environment and public utilities management relaxation; on behalf of the slacks5 means rural public management and social organization into the relaxation volume. The regression results are shown in Table 4 , Table 5.

Table 4. SFA Regression between Slacks and Environmental Variables in 2014

\begin{tabular}{|c|c|c|c|c|c|}
\hline & slacks1 & slacks2 & slacks3 & slacks4 & slacks5 \\
\hline rlf & 0.0107 & 0.00927 & 0.000248 & 0.000299 & 0.00116 \\
\hline tg & -0.000396 & -0.000443 & 0.0000217 & 0.00000400 & 0.00000222 \\
\hline ngc & -0.00135 & 0.000131 & -0.0000200 & -0.0000256 & -0.000157 \\
\hline inv & 21.28 & -1.382 & 0.165 & 0.339 & 0.488 \\
\hline eco & 2.257 & 9.523 & -2.061 & -1.248 & 0.970 \\
\hline
\end{tabular}




\begin{tabular}{|c|c|c|c|c|c|}
\hline cons & 8.381 & 8.864 & 0.657 & 0.579 & 1.033 \\
\hline $\ln \operatorname{sig} 2 \mathrm{v}$ & $6.503 * * *$ & $5.265 * * *$ & $1.477 * * *$ & -0.186 & $1.852 * * *$ \\
\hline $\ln \operatorname{sig} 2 \mathrm{u}$ & -5.486 & -5.486 & -7.813 & -8.975 & -6.564 \\
\hline
\end{tabular}

According to the SFA regression result shows, 2014 environment variables on the amount of slack effect is not significant, 2015 environment variables on the relaxation effect of significantly enhanced. Overall, relaxation and environmental variables of SFA regression coefficient significantly stronger, which showed that the environmental factors of input variables is significant. Therefore, by rejecting the environmental factors influence, in the same environment measure DMU efficiency is very necessary. From Table 5 it can be seen that under a significant level, inv and eco coefficients were negative, indicating that the state of the environment and economic development level of good areas to reduce inputs, there is conducive to the rural public investment efficiency improved, and the expected result is consistent with the rural residents own productive assets in significant levels of positive, indicating that the rural residents owned productive assets and of water conservancy, environment and public utilities management involvement is related to the use of land area of the investment amount of slack were not through the significant test, which also indirectly shows the provinces jurisdiction area of rural public investment efficiency is negligible.

Table 5. SFA Regression between Slacks and Environmental Variables in 2015

\begin{tabular}{|c|c|c|c|c|c|}
\hline & slacks1 & slacks2 & slacks3 & slacks4 & slacks5 \\
\hline rlf & 0.0270 & $0.0220^{* * *}$ & $0.0118^{* * *}$ & $0.184^{* * *}$ & 0.00563 \\
\hline $\operatorname{tg}$ & 0.00383 & 0.0000458 & 0.000102 & -0.00286 & 0.00127 \\
\hline $\mathrm{ngc}$ & -0.00241 & 0.000231 & 0.000215 & $0.00168^{* * *}$ & 0.000244 \\
\hline inv & $1.280^{* *}$ & -0.0688 & 0.00146 & $-1.002^{* *}$ & $0.417^{*}$ \\
\hline eco & $-206.0^{*}$ & -0.210 & -18.93 & 25.23 & -12.47 \\
\hline cons & $208.4^{* *}$ & -17.75 & -2.114 & $-109.6^{* * *}$ & -24.06 \\
\hline lnsig2v & -24.96 & $3.328^{* *}$ & $2.419^{* *}$ & -23.48 & $5.429^{* *}$ \\
\hline lnsig2u & $8.241^{* *}$ & -5.486 & -5.486 & $7.839^{* *}$ & -5.486 \\
\hline
\end{tabular}

\subsection{Adjusted DEA Phase}

According to the regression results and explanatory variables and explanatory variables of the significant level of SFA, the initial investments has been adjusted in 25 provinces of China, and then use the DEA software was used to analyze the efficiency and returns to scale, has adjusted the various provinces of rural public investment performance scores. Results are shown in Table 6 and Table 7.

Table 6. Score of Adjusted Efficiency of 2014

\begin{tabular}{|c|c|c|c|c|c|c|c|c|c|}
\hline province & Te & Pte & Se & & province & Te & Pte & Se & \\
\hline Hebei & 0.558 & 0.561 & 0.994 & drs & Hunan & 1.000 & 1.000 & 1.000 & - \\
\hline Shanxi & 0.573 & 0.589 & 0.973 & drs & Guangdong & 0.783 & 1.000 & 0.783 & drs \\
\hline Neimenggu & 1.000 & 1.000 & 1.000 & - & Guangxi & 1.000 & 1.000 & 1.000 & - \\
\hline Liaoning & 0.406 & 0.529 & 0.767 & drs & Hainan & 1.000 & 1.000 & 1.000 & - \\
\hline Jilin & 0.826 & 1.000 & 0.826 & drs & Sichuan & 0.856 & 0.87 & 0.984 & drs \\
\hline Heilongjiang & 1.000 & 1.000 & 1.000 & - & Guizhou & 1.000 & 1.000 & 1.000 & - \\
\hline Jiangsu & 0.801 & 1.000 & 0.801 & drs & Yunnan & 1.000 & 1.000 & 1.000 & - \\
\hline Zhejiang & 0.586 & 1.000 & 0.586 & drs & Shaanxi & 0.949 & 1.000 & 0.949 & drs \\
\hline Anhui & 0.515 & 0.686 & 0.751 & drs & Henan & 0.567 & 1.000 & 0.567 & drs \\
\hline
\end{tabular}




\begin{tabular}{|c|c|c|c|c|c|c|c|c|c|}
\hline Fujian & 0.469 & 1.000 & 0.469 & drs & Ningxia & 1.000 & 1.000 & 1.000 & - \\
\hline Jiangxi & 0.764 & 0.838 & 0.912 & drs & Qinghai & 1.000 & 1.000 & 1.000 & - \\
\hline Shandong & 0.318 & 1.000 & 0.318 & drs & Gansu & 1.000 & 1.000 & 1.000 & - \\
\hline Hubei & 1.000 & 1.000 & 1.000 & drs & mean & 0.787 & 0.909 & 0.867 & \\
\hline
\end{tabular}

From Table 6 ,we can see that 2014 environment variables on the amount of slack is not significantly affected, adjusted the efficiency scores, including technical efficiency, pure technical efficiency and scale efficiency did not change, and without the environment variables are adjusted in the DEA scores the same. In 2015, the average technical efficiency was 0.846, the average technical efficiency was 0.864 , and the average scale efficiency was 0.976 , which increased $9.05 \%, 9.92 \%$ and $19.45 \%$ respectively. From the provinces of view, adjust the former technical efficiency value does not reach the effective provinces in after adjusting the technical efficiency values were significantly increased, the technical efficiency in Hubei, Hunan, Guangxi, Sichuan, Yunnan value increased $51.85 \%, 78.03 \%, 62.50 \%$ and $57.73 \%, 63.68 \%$ respectively, the increases are all more than 50\%; pure technical efficiency value increase larger provinces of Hebei, Guangxi, Yunnan, increased $78.89 \%, 64.01 \%$, 68.65\% respectively; the scale efficiency scores (except in Guangxi and Yunnan have small amplitude decreased, other provinces have different ranges of promotion. Adjusted 8 provinces which the technical efficiency scores less than 0.5, after adjustment the scores were increased more than 0.5.

Table 7. Score of Adjusted Efficiency of 2015

\begin{tabular}{|c|c|c|c|c|c|c|c|c|c|}
\hline province & Te & Pte & Se & & province & Te & Pte & Se & \\
\hline Hebei & 0.699 & 1.000 & 0.699 & irs & Hunan & 0.543 & 0.564 & 0.964 & drs \\
\hline Shanxi & 1.000 & 1.000 & 1.000 & - & Guangdong & 0.588 & 0.616 & 0.953 & drs \\
\hline Neimenggu & 1.000 & 1.000 & 1.000 & - & Guangxi & 0.663 & 0.72 & 0.921 & irs \\
\hline Liaoning & 1.000 & 1.000 & 1.000 & - & Hainan & 1.000 & 1.000 & 1.000 & - \\
\hline Jilin & 1.000 & 1.000 & 1.000 & - & Sichuan & 1.000 & 1.000 & 1.000 & - \\
\hline Heilongjiang & 1.000 & 1.000 & 1.000 & - & Guizhou & 0.513 & 0.6 & 0.855 & irs \\
\hline Jiangsu & 0.825 & 1.000 & 0.825 & drs & Yunnan & 0.694 & 0.737 & 0.941 & irs \\
\hline Zhejiang & 1.000 & 1.000 & 1.000 & - & Shaanxi & 0.758 & 0.774 & 0.978 & irs \\
\hline Anhui & 0.724 & 0.754 & 0.96 & irs & Henan & 0.648 & 0.66 & 0.982 & irs \\
\hline Fujian & 1.000 & 1.000 & 1.000 & - & Ningxia & 1.000 & 1.000 & 1.000 & - \\
\hline Jiangxi & 0.654 & 0.654 & 1.000 & - & Qinghai & 1.000 & 1.000 & 1.000 & - \\
\hline Shandong & 1.000 & 1.000 & 1.000 & - & Gansu & 1.000 & 1.000 & 1.000 & - \\
\hline Hubei & 0.533 & 0.539 & 0.989 & irs & mean & 0.846 & 0.864 & 0.976 & \\
\hline
\end{tabular}

\section{Conclusion}

In this paper, we assess the initial efficiency of rural public investment in different provinces in China, by using the classical DEA model. When did not exclude environmental factors and random error, efficiency of public investment in rural provinces in China is low, and the differences between regions is obvious, after second stages of constructing SFA model, influence eliminate environmental factors and random error after adjusting initial input again for DEA analysis, found in China's provinces both in technical efficiency, pure technical efficiency, and scale effective, significant improvement, based on the above analysis, rural public investment capital and capital efficiency are further improved space. In our country, we should pay more attention to the improvement of the efficiency of the use of funds while increasing the public investment in rural areas. Differences between different regions of the efficiency scores also requires various provinces, the relevant departments shall, according to the actual situation in the region, the clear effect of the advantageous and disadvantageous factors of the efficiency of public investment, defined in the rural public investment direction, purpose, pay 
attention to the coordinated development of scale and efficiency, better play public investment in rural areas in the promotion of economic development in rural areas, promote the integration of urban and rural public service construction, reduce the important role of regional income disparities.

\section{Acknowledgments}

This study was financially supported by Quzhou University Key Subject Construction project: enterprise management (007214004).

\section{References}

[1] A.Antoci, S.Borghesi, "Foreign direct investments, environmental externalities and capital segmentation in a rural economy", Ecological Economics, Vol.116, (2015), pp.341-353.

[2] R.Testa, "Choice between alternative investments in agriculture: The role of organic farming to avoid the abandonment of rural areas",Ecological Engineering, Vol.83, (2015), pp.227-232.

[3] E.Kerselaers, E.Rogge, "Changing land use in the countryside: Stakeholders' perception of the ongoing rural planning processes in Flanders”,Land Use Policy, Vol.32, (2013),pp.197-206.

[4] X.B. Lastra-Bravo, C.Hubbard, "What drives farmers' participation in EU agri-environmental schemes?: Results from a qualitative meta-analysis", Environmental Science \& Policy, Vol.54, (2015), pp.1-9.

[5] H.B.Glick, C.Bettigole, "Wyoming's Aging Agricultural Landscape: Demographic Trends Among Farm and Ranch Operators, 1920-2007”, Rangelands, Vol.36, (2014), pp.7-14.

[6] Y,Tang, R,J. Mason, “Governments' functions in the process of integrated consolidation and allocation of rural-urban construction land in China”,Journal of Rural Studies, Vol. 42, (2015),pp. 43-51.

[7] M.Yazdanpanah, F.Feyzabad, "Predicting farmers' water conservation goals and behavior in Iran: A test of social cognitive theory",Land Use Policy, Vol. 47, (2015), pp.401-407.

[8] I.D. Hodge, W.M. Adams, "Property institutions for rural land conservation: Towards a post-neoliberal agenda", Journal of Rural Studies, Vol.36, (2014), pp.453-462.

[9] T.K. Rudel, P.Meyfroidt, "Organizing anarchy: The food security-biodiversity-climate crisis and the genesis of rural land use planning in the developing world", Land Use Policy, Vol.36, (2014), pp.239247.

[10] C.Bittner, M.Sofer, "Land use changes in the rural-urban fringe: An Israeli case study",Land Use Policy, Vol.33, (2013), pp.11-19. 
International Journal of Grid and Distributed Computing Vol.9, No.5 (2016) 